\title{
New directions for the Annual Review of Applied Linguistics
}

\author{
Alison MACKEY \\ Editor-in-chief, the Annual Review of Applied Linguistics
}

To begin with some history, reflecting the breadth of the field, the 35 issues of the Annual Review of Applied Linguistics (ARAL) published since 1980 have covered a substantial range of topics. These have included broad surveys of the field of applied linguistics; language and language-in-education; identity; written discourse; literacy; bilingual communities worldwide; language and the professions; communicative language teaching; second language acquisition research; discourse analysis; issues in foreign language teaching and learning; language policy and planning; technology and language; multilingualism; foundations of second language teaching; applied linguistics as an emerging discipline; language and psychology; discourse and dialogue; language contact and change; advances in language pedagogy; lingua franca languages; neurolinguistics; cognitive aspects of language processing; language assessment; and formulaic language.

Last year, the 35th issue brought some changes for the journal. Cambridge University Press and the American Association for Applied Linguistics (AAAL) renegotiated their contract. Reflecting members' increased use of online resources, members will no longer receive a print copy as part of their membership. Instead, ARAL is now available to the membership online, along with all the back issues. The 35th issue of the journal (2015), (http://journals.cambridge.org/action/displayJournal?jid=APL) also saw a fresh, new print design and updated cover. This issue focused on identity in applied linguistics, which was also the theme of the 2015 AAAL conference. The decision to bring together the conference theme and the journal theme aimed to promote greater visibility and accessibility.

The editorial board has decided to continue to tie the theme of the journal to the conference every few years. This will exploit synergies across media and contexts, reflect the interests of the membership of AAAL, and also allow the journal to continue to cover a wide range of issues and debates in the field of applied linguistics. The publication date has also been brought forward, to make ARAL available in print at the time as the annual AAAL conference so that members can see and hear about the current year's issue during the conference.

For this current issue (2016, the 36th), ARAL's editorial board has continued the long-standing tradition of striving to improve the journal. For the first time, this year's ARAL includes not only the traditional review articles that provide state-ofthe-art overviews of the field, but also a range of other types of articles, including position pieces, empirical papers showcasing new data, methodologically focused work, and meta-analyses/syntheses. Our goal is for ARAL to continue its role as a valuable resource for the community, with one annual focus on a specific topic 
of high interest and importance for the field. Starting this year, we have expanded its coverage to review a topic from a wide range of perspectives.

Turning to the content of this exciting new issue of ARAL, the current focus is the theme of tasks in applied linguistics. The current issue begins with a polemical article by Long, in which he addresses various criticisms of task-based learning and teaching. Long incisively explains and evaluates problems that have been raised in relation to tasks and task-based teaching, characterizing them as either nonissues or real issues.

Skehan's piece, which follows, also offers a theoretical perspective on second language tasks. This article explores the important contrast between the effects on second language performance of tasks and task characteristics, on the one hand, and the conditions under which tasks are carried out, on the other.

Also covering frameworks for task-based learning and teaching, but from a different angle, is an article by Philp and Duchesne, who explore the construct of task engagement in language classrooms. They discuss key concepts and indicators of engagement in current research on task-based interaction and describe some of the critical issues that need to be considered when studying factors that contribute to how engaged students are in classroom tasks.

Following these three different positions in relation to tasks, the next set of articles focuses on the methodology of how research is carried out. A meta-analysis by Plonsky and Kim begins this section. They provide a systematic review of studies that analyze task-based learner language. Their results add both to the growing body of methodological syntheses and to the broader methodological reform movement taking place in applied linguistics; echoing this movement, they call for more detailed reporting and replication.

Foster and Wigglesworth's piece provides the kind of innovation that Plonsky and Kim call for. They review a wide variety of methods for measuring linguistic accuracy before presenting a new proposal for a weighted clause ratio measure that classifies errors at different levels. They differentiate between errors that seriously impede communication, those that impair communication to some degree, and those that do not impair communication at all, proposing a new way forward in the thorny issue of how to measure one of the outcomes of tasks.

Gilabert, Manchón, and Vasylets take up another call for more research in the task literature by exploring how mode (understood as oral/aural and written output) may induce and/or influence tasks and second language acquisition processes. Their analysis provides implications for task-based language learning and teaching theorizing, task design, and classroom practices. Their focus on writing is a welcome addition to a task-based literature that, with a few important exceptions, has hitherto focused primarily on spoken input and output.

Finishing this section, Ziegler's review article provides an update on a topic that is receiving increasing attention in the task field, and in the area of applied linguistics as a whole: the role of technology in language learning. Her state-ofthe-art review shows how technology-mediated, task-based learning and teaching facilitate and support second language development and performance, and also how technology can contribute to our understanding of how aspects of this approach, 
such as task-design features and task implementation, can influence the success of second language acquisition.

Following these methodological and review articles, we turn to the critical aspect of teachers in tasks. Van den Branden's position piece takes issue with the scant attention paid in the previous applied linguistics literature to the role of the teacher in second language learning tasks and pedagogy. He approaches this issue in task-based learning and teaching from three perspectives: teachers as mediators of the students' language development, as key figures in the implementation of task-based approaches, and as researchers furthering the field.

Reflecting that important point made by Van den Branden, that the study of tasks in applied linguistics necessarily involves the roles and perspectives of teachers as well as researchers, another forward-looking empirical article by Révész and Gurzynski-Weiss goes beyond the majority of existing empirical studies on how tasks should be graded and sequenced (a topic of critical importance in Robinson's influential contributions to the task literature, as they explain). They use a data-driven bottom-up approach in order to explore what makes tasks difficult (or easy) from teachers' perspectives. Their exploratory study asked teachers to think aloud while their eye movements were tracked. This interesting triangulation of introspective and behavioral data advances our understanding of linguistic and conceptual demands in teachers' beliefs about task difficulty.

A final empirical piece by Li, Ellis, and Zhu reflects a more constrained view of tasks than the one presented initially by Long, and after outlining their position, the authors describe an empirical investigation comparing the effectiveness of task-based and task-supported instruction in the acquisition of the English passive construction. They argue that both task-based and task-supported instruction facilitate the acquisition of explicit knowledge, especially when coupled with explicit instruction followed by within-task feedback.

The issue concludes with a contribution by Norris, who writes about tasks in relation to language assessment. This is another important area of task research in applied linguistics with its own set of foci.

Of course, there are many more perspectives on tasks and task-based learning than the ones that could be included in this issue. However, with its focus on theory, methodology, empiricism, technology, new techniques, and teachers, this issue provides a telling snapshot of the wealth of productive work that exists in the area of tasks and applied linguistics, as well as some exciting new directions, avenues, and techniques for future research.

Although the articles were invited, each was reviewed by a member of the editorial board as well as by at least two (and sometimes as many as five) external reviewers. The editorial board provides ideas for the focus of each issue at the annual meeting, and once a decision has been made, follows up with specific suggestions about who should be invited to contribute based on their areas of expertise. I would like to thank all of the individuals on the editorial board; the outgoing editor from 2014, Charlene Polio, who helpfully shared everything with me; and all of the external reviewers, who gave their time, effort, and energy in feedback, always on a very tight schedule, including Missy Baralt, Jaemyung 
Goo, YouJin Kim, Ken Petersen, Rebecca Sachs, Jong-Bong Lee, Bryan Smith, and others who prefer to remain anonymous. Many of the authors also provided timely, helpful, and constructive feedback to each other, for which we are all grateful. Participants in useful early discussions about what this issue might cover include Martin Bygate, Virginia Samuda, Marta González-Lloret, Marita Schocker, Andreas Müller-Hartmann, and Marije Michel, all of whose work and comments on tasks in applied linguistics helped shape this volume. I also thank our publisher, Melissa Good, who is a strong and generous advocate for this journal, and the staff at Cambridge University Press, including Edward Carey and Emily Throne. I am grateful to the executive committee of AAAL, which put forward editorial board members who gave valuable advice and support. This year, Kendall King and Laura Collins of AAAL each provided extremely helpful input on this issue. Aneta Pavlenko, in her role as both AAAL president and ARAL editorial board member, inspired us to think outside the box and discuss the many ways we could reimagine the journal for a new generation of applied linguists. Finally, I would like to thank three Georgetown University students: Julia Goetze and Young-A Son, who were extremely helpful in putting this issue together, and Lara Bryfonski, the ARAL editorial assistant, who consistently outdid herself with speed and efficiency. 